\title{
0 trabalhador estudante em um curso de bacharelado e licenciatura em enfermagem: trajetórias e desafios
}

\author{
The worker student pursuing Licentiate and Bachelor's \\ degree in Nursing: journey and challenges
}

El trabajador estudiante em un curso de Bachillerato $y$ Licenciatura en Enfermeria: trayectorias y desafios

GABRIELA MARIA PREBILL (D)

ADRIANA KATIA CORRÊA (iD b

\section{Resumoc $^{c}$}

Nas últimas décadas, tem havido um processo de expansão do ensino superior no Brasil, considerando políticas internacionais e nacionais. A área da enfermagem insere-se também nesse processo, com expansão de vagas, principalmente em cursos noturnos em instituições de ensino superior (IES) privadas. Nesse contexto, faz-se presente a possibilidade de inserção de trabalhadores nas IES. O estudo teve como objetivo compreender a trajetória do trabalhador estudante no curso de Bacharelado e Licenciatura em Enfermagem de uma instituição de ensino superior pública. Tratou-se de estudo qualitativo, descritivo-exploratório, que utilizou entrevista semiestruturada como técnica de coleta de dados e análise

\footnotetext{
a Universidade de São Paulo (USP), Escola de Enfermagem de Ribeirão Preto, Ribeirão Preto, SP, Brasil. Graduada em Bacharelado e Licenciatura em Enfermagem, e-mail: gabiprebill@hotmail.com

b Universidade de São Paulo (USP), Escola de Enfermagem de Ribeirão Preto, Ribeirão Preto, SP, Brasil. Doutora em Enfermagem, e-mail: adricor@eerp.usp.br

' Este artigo é resultado da dissertação de mestrado intitulada "O trabalhador estudante de enfermagem: trajetórias e desafios" apresentada à Universidade de São Paulo no ano de 2019.
} 
temática de conteúdo para análise dos mesmos. Envolveu trabalhadores estudantes egressos que ingressaram no curso entre os anos de 2006 e 2013. Os trabalhadores estudantes entrevistados eram, na maioria, auxiliares/técnicos em enfermagem e vislumbraram a possibilidade de conciliar trabalho e estudo ao ingressar no curso. A trajetória prévia na educação básica pública se apresentou como fator limitador para a continuação dos estudos em nível superior. A procura pelo curso relacionou-se a uma possibilidade de inserção rápida ou permanência no mercado de trabalho. Algumas vivências dos trabalhadores estudantes envolveram o não reconhecimento do direito da sua inserção, como trabalhador no curso. Os participantes valorizaram a trajetória individualizada, estando em consonância com a lógica neoliberal. Os resultados obtidos podem subsidiar reflexões sobre a forma como a inserção de trabalhadores no ensino superior tem sido compreendida nos espaços de formação docente e de tomada de decisões institucionais.

Palavras-chave: Estudantes. Trabalhadores. Educação Superior. Formação Profissional.

\begin{abstract}
Over the last decades, Brazilian higher education has expanded regarding international and national policies. The Nursing area has also been part of this process, whose slots, especially for night classes at private Higher Education Institutions (IES), have also grown. In this context, the possibility of workers to obtain access to the IES must be considered. The study aimed to understand the trajectory of the student worker in the Bachelor and Licentiate Degree in Nursing at a public higher education institution. This was a qualitative, descriptive-exploratory study, which used semi-structured interviews as a technique for data collection and thematic content analysis for their analysis. It involved student worker graduates who entered the course between the years 2006 and 2013. The student workers interviewed were mostly nursing assistants/technicians and envisioned the possibility of reconciling work and study when entering the course. The previous trajectory in public basic education was presented as a limiting factor for the continuation of studies in higher education. The demand for the course was related to the possibility of quick insertion or permanence in the job market. Some experiences of student workers involved the lack of recognition of the right to their insertion, as a worker in the course. The participants valued the individualized trajectory, being in line with the neoliberal logic. The results obtained can support reflections on how the insertion of workers in higher education has been understood in the spaces of teacher training and institutional decision-making.
\end{abstract}

Keywords: Students. Workers. Higher Education. Professional training. 


\section{Resumen}

En las últimas décadas, ha habido un proceso de expansión de enseñanza superior en Brasil, considerando políticas internacionales y nacionales. El área de la enfermería se inserta, también, en ese proceso, con expansión de plazas, principalmente en cursos nocturnos en institución de enseñanza superior (IES) privadas. En ese contexto, se hace presente la posibilidad de inserción de trabajadores en las IES. El estudio tuvo como objetivo comprender la trayectoria del estudiante trabajador en lo Bachillerato y Licenciatura en Enfermería en una institución pública de educación superior. Este fue un estudio cualitativo, descriptivo-exploratorio, que utilizó entrevistas semiestructuradas como técnica para la recolección de datos y el análisis de contenido temático para su análisis. Involucró a estudiantes graduados trabajadores que ingresaron al curso entre los años 2006 y 2013. Los estudiantes entrevistados eran en su mayoría auxiliares/técnicos de enfermería y vieron la posibilidad de conciliar el trabajo y el estudio al ingresar al curso. La trayectoria previa en la educación básica pública se presentó como un factor limitante para la continuación de los estudios en educación superior. La demanda del curso se relacionó con la posibilidad de inserción o permanencia rápida en el mercado laboral. Algunas experiencias de estudiantes trabajadores implicaron la falta de reconocimiento del derecho a su inserción, como trabajador nel curso. Los participantes valoraron la trayectoria individualizada, en línea con la lógica neoliberal. Los resultados obtenidos pueden respaldar reflexiones sobre cómo se ha entendido la inserción de los trabajadores en la educación superior en los espacios de capacitación docente y toma de decisiones institucionales.

Palabras clave: Estudiantes. Trabajadores. Educación Superior. Formación Profesional.

\section{Introdução}

Nas últimas décadas, tem havido um processo de expansão do ensino superior caracterizado por forte influência de políticas internacionais de cunho neoliberal demandando, desse nível de ensino, o atendimento mais ágil às demandas de mercado e a expansão da rede privada (AGUIAR, 2010; ZAGO; PAIXÃO; PEREIRA, 2016; MANCEBO, 2017). Entretanto, em 2002, o Brasil passou por mudança de governo, sendo propostas políticas públicas de ensino superior que favoreceram também a ampliação e o fortalecimento de Instituições de Ensino Superior (IES) públicas e o desenvolvimento de políticas de inclusão e permanência estudantil (VARGAS; PAULA, 2013; CUNHA, 2014; MANCEBO, 2017). 
Como parte integrante do processo de expansão do ensino superior, principalmente no setor privado, e do crescimento acentuado de centros universitários, no governo FHC, de 1995 a 2001, o número de alunos matriculados em cursos noturnos em IES privadas dobrou (CUNHA, 2003).

No âmbito estadual, particularmente no estado de São Paulo, a oferta de vagas para o ensino superior noturno, nas três principais universidades estaduais paulistas, Universidade Estadual Paulista "Júlio de Mesquita Filho" (UNESP), Universidade Estadual de Campinas (UNICAMP) e Universidade de São Paulo (USP), atende à exigência da Constituição Paulista, de um terço do total de suas vagas destinadas ao período noturno (BARREIRO; TERRIBILI FILHO, 2007).

Embora a USP, instituição na qual se insere o curso que será foco deste estudo, atinja o objetivo estabelecido pela Constituição Paulista de oferta de vagas noturnas, há um desequilíbrio entre as áreas de conhecimento. Barreiro e Terribili Filho (2007) descrevem que, nessa universidade, em 2006, 34,8\% das vagas foram destinadas ao período noturno, porém apenas 16,5\% foram destinadas às ciências biológicas, área na qual se enquadra o curso analisado neste estudo, enquanto 25,8\% foram destinadas às ciências exatas e 50,2\%, às ciências humanas.

Nesse contexto, observa-se, mesmo dentro do ensino superior público, a seletividade da educação brasileira, uma vez que alunos de baixa renda precisam do trabalho como forma de sustento e, ao procurar o ensino superior para a ascensão social, têm menores possibilidades de ingresso em cursos mais econômica e socialmente valorizados.

Ao analisar a relação concluintes/ingressantes em Instituições Federais de Ensino Superior (IFES), no período de 2001 a 2010, Vargas e Paula (2013) concluíram que a proporção de concluintes em relação à de ingressantes vem decaindo discretamente, mesmo em meio à aplicação de políticas de inclusão e permanência estudantil. No ano de 2010, do total de alunos das IFES, 37,63\% trabalhavam e, dessa porcentagem, 30,4\% eram oriundos das classes econômicas C, D e E. As autoras ainda comentam que, embora as razões para esse declínio sejam multicausais, a hipótese do trabalho como obstáculo à conclusão do ensino superior precisa ser considerada razoável. 
Em estudo realizado com estudantes da Universidade Federal de Santa Catarina oriundos de famílias de baixo poder aquisitivo, Zago (2006) concluiu que o tempo investido no trabalho, como forma de sobrevivência, impõe certos limites acadêmicos, principalmente relacionados à participação em encontros organizados para trabalhos coletivos com colegas, congressos e conferências científicas ou mesmo atividades extracurriculares de complementação acadêmica.

De acordo com Filho e Raphael (2005), a demanda para o ensino superior noturno é caracterizada por estudantes que trabalham durante o dia, em áreas não necessariamente relacionadas ao curso escolhido. São estudantes que enfrentam de modo mais intenso problemas diários relacionados a trânsito e transporte público, culminando em atrasos e perdas de aulas. Barreiro e Terribili Filho (2007) destacam que, em geral, esses estudantes estão em busca de reconhecimento social, formação profissional e obtenção de diploma na expectativa de aumentar suas chances de competir no mercado de trabalho.

$\mathrm{Na}$ área da enfermagem houve, também, expansão de vagas, principalmente em cursos noturnos em IES privadas (BRASIL, 2013; BRASIL, 2019). Considerando a política de ampliação de vagas das IES estaduais no estado de São Paulo, com foco no ensino superior noturno, teve início o curso de Bacharelado e Licenciatura em Enfermagem de uma Instituição de Ensino Superior (IES) pública, com oferta de 50 vagas, no período vespertino/noturno (14 às 23 horas), em 2006 (CORRÊE; SOUZA; CLAPIS, 2016).

O projeto político pedagógico desse curso descreve, além da formação do enfermeiro generalista, a formação pedagógica para o trabalho do enfermeiro como professor nas escolas que ministram educação profissional técnica de nível médio em enfermagem (formação de auxiliares e técnicos de enfermagem). O curso traz também a possibilidade de ampliação de vagas e ingresso de pessoas que trabalham (CORRÊA; SOUZA; CLAPIS, 2016).

Apesar da possibilidade de ingresso de pessoas que trabalham não ter sido o foco principal da abertura desse curso, trata-se de um ponto importante a ser discutido, na medida em que representa, explicitamente, uma forma de ampliação do acesso das camadas populares à universidade. Além disso, traz demandas para as 
formas de gerir o curso e de produzir o trabalho pedagógico, no contexto do processo formativo.

A inserção do trabalhador estudante no ensino superior público é temática pouco enfocada na área da enfermagem. Em pesquisa bibliográfica realizada pelas pesquisadoras do presente estudo, constatou-se que a produção científica voltada para o trabalhador estudante de enfermagem aponta para a procura pelo ensino superior voltada para a melhoria das condições socioeconômicas, a ascensão profissional e social, que são relacionadas, pelos trabalhadores, à melhoria da qualidade de vida para si e para os familiares. Entretanto, foram observados aspectos dificultadores para a trajetória acadêmica, como limites gerados pelo ingresso tardio no ensino superior, dificuldades financeiras e para conciliar estudo e trabalho, baixa qualidade de vida e rendimento acadêmico insatisfatório (PREBILL; CORREAA, 2018), o que vem ao encontro de pesquisas realizadas com trabalhadores alunos de outras áreas.

Sendo assim, partindo das demandas apontadas na produção científica sobre o trabalhador estudante de áreas profissionais diversas e de enfermagem, bem como do contexto político da educação superior no Brasil, questionou-se se as situações pontuadas e discutidas nesses textos estão também presentes nas vivências dos trabalhadores estudantes do curso enfocado neste estudo.

Este estudo tem como objetivo geral compreender a trajetória do trabalhador estudante no curso de Bacharelado e Licenciatura em Enfermagem de uma IES pública do estado de São Paulo. Como objetivos específicos: compreender a trajetória escolar, construída na educação básica, e suas relações com a inserção na universidade e a escolha profissional; compreender os motivos que levaram à escolha pelo ingresso no curso de Bacharelado e Licenciatura em Enfermagem; compreender as relações que se configuram entre os sujeitos envolvidos no processo educativo.

\section{Trajetória metodológica}

O presente artigo é fruto de um estudo qualitativo, de natureza descritivoexploratória (MINAYO, 2012; POUPART et al., 2014), realizado com trabalhadores estudantes egressos de um curso de Bacharelado e Licenciatura em Enfermagem de 
uma universidade pública do estado de São Paulo, que ingressaram entre os anos de 2006 e 2013.

Para acesso aos trabalhadores, partiu-se de dados de outra pesquisa desenvolvida pelas autoras, no período de 2006 a 2016 (CORRÊEA et al., 2018), cujo objetivo foi traçar o perfil de alunos ingressantes nesse curso. De posse da lista de ingressantes trabalhadores, foram destacados os potenciais participantes e separados por turma de ingresso. Foram sorteados dois participantes por turma e realizado contato, por meio das redes sociais Facebook ${ }^{\circledR}$ e LinkedIn $\AA$, telefone e e-mail, para identificar se os participantes se enquadravam nos critérios de inclusão.

Foi incluído o participante que se inseriu no curso exercendo atividade remunerada, seja com vínculo empregatício formal ou em atividade informal, assim se manteve, até pelo menos o término do terceiro ano de graduação, e concluiu o curso. Esses critérios justificaram-se pela possibilidade de contato com alunos que tiveram experiência de conciliar trabalho e estudos por período não pontual.

Foram excluídos egressos que, no momento do ingresso do curso, não exerciam atividade formal ou informal remunerada, e que, no momento do ingresso do curso, exerciam atividade formal ou informal remunerada, porém não conciliaram trabalho e estudo até, pelo menos, o término do terceiro ano de graduação. Foram excluídos, também, participantes que não retornaram o contato inicial realizado pela pesquisadora após duas tentativas ou que retornaram o contato após o prazo estabelecido pela mesma para a coleta de dados (janeiro a julho de 2019). Considerando esse último critério estabelecido, não foi possível a inclusão de alunos que ainda fazem o curso envolvido. Nos casos em que a pessoa não se enquadrou nos critérios ou não respondeu ao contato inicial no tempo estipulado pela autora, foi realizado novo sorteio.

A proposta inicial envolvia a coleta de dados com graduandos e egressos que estavam conciliando trabalho e estudo no curso no momento da coleta de dados. Entretanto, no período estabelecido para a coleta de dados, foram encontradas dificuldades no contato com trabalhadores ainda graduandos, dadas as condições vivenciadas pelos mesmos no que se refere a horários disponíveis para a participação na pesquisa. Assim, este estudo esteve focado nos dados trazidos pelos egressos, portanto, ingressantes entre 2006 e 2013, conforme descrito. 
A coleta de dados foi realizada entre janeiro e julho de 2019, por meio de entrevistas semiestruturadas. A entrevista semiestruturada possibilita que $O$ entrevistador tenha a liberdade de desenvolver e direcionar o diálogo, de modo a explorar amplamente as questões trazidas pelos participantes (LAKATOS; MARCONI, 2017).

No total, foram realizadas nove entrevistas. Sete entrevistas foram realizadas presencialmente; duas por telefone e gravadas mediante autorização prévia dos entrevistados. Todas as entrevistas foram transcritas posteriormente.

Após a transcrição das entrevistas, os dados foram analisados por meio de análise temática de conteúdo. Ao considerarmos pesquisa qualitativa aquela capaz de incorporar o significado e a intencionalidade como inerentes aos atos, às relações e às estruturas sociais, a análise de conteúdo é compreendida como um método de organização e análise de dados que tem como objetivo qualificar as vivências dos sujeitos, assim como as suas percepções sobre determinado objeto ou fenômeno. É constituída por técnicas para descrever o conteúdo emitido no processo de comunicação de forma a associá-lo com as questões teóricas que vão ao encontro dos objetivos propostos pelo estudo. A análise é realizada por meio de três fases, sendo elas: a "pré-análise", a "exploração do material" e o "tratamento dos resultados” (BARDIN, 2016). Foram configuradas três categorias de análise.

Essas categorias foram apresentadas de forma descritiva, utilizando-se trechos das entrevistas identificados pela inicial "E" e pelo número da entrevista. Ao mesmo tempo, foram relacionadas às ideias de autores que enfocam aspectos que ajudam a compreender a temática em foco contextualizada no cenário político econômico atual. Nessa contextualização, há uma aproximação inicial à perspectiva teórica que traz à tona alguns aspectos da relação entre o acesso à educação e a sociedade capitalista.

Esta pesquisa foi aprovada pelo Comitê de Ética em Pesquisa (CEP) da IES na qual o curso está inserido, conforme estabelece a Resolução CNS 510 de 2016, que dispõe sobre as normas para pesquisas em ciências humanas e sociais envolvendo dados obtidos com participantes, pelo Parecer 2.895.674/2018. 


\section{Resultados e discussão}

Dos nove participantes entrevistados, sete eram do sexo feminino. Dessas, três eram casadas e/ou conviviam com algum(ma) companheiro(a), três tinham filhos e, entre essas, uma delas declarou-se divorciada e uma solteira. Embora este estudo parta de um recorte dos trabalhadores estudantes no curso em foco, a predominância de participantes sorteados que eram mulheres pode estar relacionada à própria predominância do sexo feminino apresentada no curso estudado e, em geral, em cursos de enfermagem (SPÍNDOLA et al., 2008; NARDELLI et al., 2013; SOUZA et al., 2013; BUBLITZ et al., 2015; CORRÊA et al., 2018).

Somado a isso, considerando que a maioria dos participantes do presente estudo foram mulheres e que uma expressiva parcela tinha filhos, torna-se importante a reflexão sobre as características relacionadas à conciliação de trabalho, estudo e família como mulheres e mães.

No que se refere à raça/cor, seis participantes se identificaram como brancos, um como negro e um como pardo. A proporção de participantes que se autodeclararam brancos ser maior do que os que se autodeclararam negros ou pardos pode estar relacionada à proporção de estudantes brancos e negros em IES no geral. Ristoff (2014) identificou que, embora os brancos representem $48 \%$ da população brasileira, essa porcentagem é maior em relação à população negra inserida em IES. Ainda, segundo o autor, cursos considerados mais concorridos tendem a ter percentuais ainda menores de negros.

Quanto à trajetória escolar, oito dos nove entrevistados realizaram todo o ensino fundamental em instituições de ensino públicas. Quando questionados sobre a escolarização no ensino médio, sete participantes cursaram em instituições de ensino públicas. Sobre a escolaridade das mães dos participantes, dois tinham mães com ensino fundamental completo, quatro com ensino fundamental incompleto, um com ensino médio completo e dois com ensino superior completo, com formação em pedagogia e gestão ambiental. Sobre a escolaridade dos pais, dois não tinham escolaridade, quatro tinham ensino fundamental incompleto e três tinham ensino médio completo. 
Assim como nas IES públicas, os estudantes de enfermagem têm pais com nível de escolaridade, em média, na categoria "ensino médio", sendo que a escolaridade da mãe, quando comparada à do pai, é ligeiramente superior, mas mantendo maiores concentrações no ensino médio (BRASIL, 2013). Neste estudo por ora apresentado predominou escolaridade dos pais como ensino fundamental

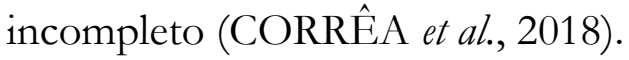

Palazzo e Gomes (2012) descrevem que pessoas oriundas de níveis socioeconômicos mais elevados tendem a ingressar em cursos de maior prestígio social, enquanto estudantes oriundos de famílias com menor nível de escolarização tendem a ingressar em cursos menos valorizados, como as licenciaturas/formação para a docência, denotando um processo de desigualdade na democratização do

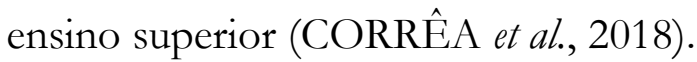

Durham (2003) descreve que há três fatores que implicam decisivamente o êxito escolar: a renda familiar, a ascendência étnica e a escolaridade dos pais. Segundo Pinto (2004), a influência das escolaridades dos pais na escolha da carreira dos filhos ocorre a partir do momento em que pais que têm níveis mais elevados de ensino tendem a ter famílias com renda familiar alta, o que influencia os filhos a optarem por carreiras com maior retorno salarial. A situação de escolaridade das mães e pais dos participantes deste estudo tem, pois, possível congruência com a escolha profissional pela formação como enfermeiro licenciado (CORRÊA et al., 2018).

A idade de ingresso no curso obteve média de 29 anos, sendo que o participante que ingressou no curso com menor idade possuía 24 anos e o participante que entrou no curso com a maior idade possuía 40 anos. A média de idade, provavelmente, tem relação não somente com o fato de os participantes serem trabalhadores, mas com a especificidade de o curso em foco ter sido recentemente implantado, o que será retomado.

Considerando que o início de oferta do curso ocorreu em 2006, ao retomar o Plano Nacional de Educação (PNE 2001-2010), é possível observar que a média de idade dos trabalhadores ingressantes participantes no presente estudo está consideravelmente acima do estabelecido para o ingresso no ensino superior. $O$ PNE visava prover, até o final da década, a oferta de educação superior para, pelo 
menos, 30\% da faixa etária de 18 a 24 anos, porém, em 2010, atingiu 12\% da matrícula dessa parcela da população (AGUIAR, 2010).

Nesse sentido, Aguiar (2010) descreve que as metas de conclusão e matrícula no ensino médio, no período, também não foram atingidas e os investimentos em estratégias esbarram nas condições de vida dos estudantes, uma vez que busca de trabalho é considerado um fator bastante relevante. Observa-se, portanto, no que concerne ao trabalhador estudante, um atraso no ingresso no ensino superior, em relação a metas estabelecidas.

Todos os participantes ingressaram trabalhando e trabalharam durante todo o curso, sendo cinco como auxiliares de enfermagem, um como técnico de enfermagem, um como agente de controle de endemias e dois em funções administrativas.

Percebe-se, portanto, um movimento de auxiliares e técnicos de enfermagem que buscaram o ensino superior para a formação de enfermeiros. Em pesquisa realizada para traçar o perfil da enfermagem no Brasil, foi identificado um movimento expressivo de técnicos e auxiliares que, a partir da vivência no trabalho, buscaram a graduação em enfermagem. Dos enfermeiros que participaram da pesquisa, em contexto nacional, 31,4\% realizaram, antes de se graduar, curso técnico ou auxiliar de enfermagem. Dos mais de 130 mil enfermeiros que cursaram curso de auxiliar e técnico de Enfermagem antes de se graduarem, 86,1\% declararam ter exercido a atividade e 51\% deles declararam que trabalharam antes de completar a graduação (MACHADO et al., 2016).

Após a caracterização geral dos participantes, apresentam-se a seguir as categorias de análise para a abordagem do tema apresentado.

\section{Da educação básica ao ingresso no ensino superior: a trajetória do trabalhador}

Os trabalhadores estudantes vislumbraram no curso noturno uma possibilidade de formação no ensino superior por terem condições de conciliar trabalho e estudo, dado o período de oferecimento do curso incluir o noturno. Essa possibilidade se relaciona a estudos anteriormente citados, como Terribili Filho e Raphael (2005) e Barreiro e Terribili Filho (2007). 
Nesse contexto, a formação prévia construída majoritariamente na educação básica pública foi apresentada, pelos entrevistados, como fator influenciador e, ao mesmo tempo, limitador na trajetória individual em direção à educação superior.

Essa limitação foi expressa uma vez que a possibilidade de ingresso na universidade ocorreu somente a partir do momento em que alguns entrevistados foram informados, por profissionais da IES que estavam exercendo atividade de ensino em estágio nas instituições de serviços de saúde nas quais os egressos entrevistados exerciam suas atividades laborais, sobre as características do curso Bacharelado e Licenciatura em foco: início recente e, portanto, com possível baixa procura, nota de corte menor, naquele momento, do que outros cursos, e período de oferecimento noturno.

(...) e que na USP era muito difícil passar, que eu não tinha nem esperança. Mas aí ela falou pra mim desse curso novo que ia começar de licenciatura em enfermagem, e que de repente eu poderia ter uma chance, de repente. Não era muito bem divulgado, era uma coisa nova, muita gente não optaria por ele (...). E01

(...) eu venho de uma escola pública, eu não tinha preparação para passar num vestibular até que eu fiz dois anos de cursinho pré-vestibular e influenciou que a licenciatura, o curso de licenciatura em Enfermagem era mais palpável para a minha realidade. A nota de corte do que os outros cursos. E02

Assim, para alguns, o curso "veio até eles", sendo algo que aconteceu como uma possibilidade em suas vidas até então não claramente pensada, tendo em vista que, em suas concepções prévias, a universidade não é espaço para eles, devido às dificuldades impostas pelos exames vestibulares, limitando o acesso de pessoas que têm trajetória de educação básica na escola pública.

Girotto (2017), a partir de dados de pesquisa cujo foco é a inserção da classe trabalhadora na universidade em um curso de geografia, comenta que há uma construção histórica de um processo de distanciamento entre a educação básica e a educação superior e, mesmo as políticas de acesso ao ensino superior não têm dado conta de desconstruir esse processo.

Percebe-se que, ao mesmo tempo em que a formação na educação básica, na visão dos entrevistados, não forneceu condições para o ingresso no ensino superior público, o trabalhador estudante também relatou que as suas condições financeiras não eram favoráveis à busca pelo ensino superior privado. 
Apesar da implantação de políticas afirmativas e da expansão de vagas ocorridas no ensino superior, principalmente de IES privadas, o ingresso de alunos de camadas populares no ensino superior permanece sendo um rompimento de um destino social provável de interrupção dos estudos devido a empecilhos financeiros, baixa qualidade da escolarização na educação básica e falta de informação sobre o acesso às universidades públicas (PIOTTO; ALVES, 2016).

Nesse contexto, apreendem-se as relações entre a classe social e a trajetória escolar e profissional dos indivíduos no modo de produção capitalista. Ao trabalhador, proveniente de classe socioeconômica menos favorecida, foi necessário o ingresso no mercado de trabalho logo após a formação na educação básica, e a possibilidade de inserção no ensino superior se deu apenas, no contexto deste estudo, a partir do momento em que esse ingresso é, de certo modo, facilitado pelas características do curso, com poucos anos de implantação, anteriormente mencionadas.

As políticas públicas de ensino voltadas a camadas populares seguem uma lógica de qualidade precária para que a classe trabalhadora seja, de certa forma, direcionada à qualificação profissional técnica, transformando a educação em um instrumento funcional ao processo de reprodução do capital e intensificação dos processos de exploração dos trabalhadores (OLIVEIRA, 2015).

Assim, a educação para o trabalho reflete a divisão de classes por meio de uma formação acadêmica para a elite e uma formação instrumental para a classe trabalhadora, o que se conceitua como dualidade estrutural, especificamente no caso, na educação (SIGNORI; CAMPANELLI, 2015).

A dualidade estrutural compreende a fragmentação da escola na qual são diferenciados os caminhos segundo a classe social, direcionando os indivíduos para postos antagonistas na divisão social do trabalho, seja para o lado dos explorados ou para o lado da exploração. No modo de produção capitalista, a dualidade da escola é expressa como resultado de mecanismos internos e pedagógicos que reproduzem as classes sociais (CAMPELLO, 2019).

Nesse sentido, embora a escolarização de jovens no Brasil tenha atingido um efetivo crescimento, ela reflete um paradoxo entre a universalização do acesso e as condições reais para a sua realização e intencionalidade pedagógica. A despeito de ser compreendida como um direito social, essa escolarização é tratada, por meio de 
políticas públicas, como privilégio de alguns segmentos, uma vez que os sistemas educacionais são fundamentados na distribuição desigual do capital simbólico da escola. A expansão da escola proporciona o ingresso de camadas populares e o que se percebe é uma mudança institucional de esvaziamento de formação cidadã e igualitária de oportunidades para uma reprodução das relações sociais de produção. Essa transformação define a escola pública de educação básica em escolas para pobres(SIMÕES, 2010). E essa concepção, como visto, traz implicações para a continuidade dos estudos nas IES públicas.

\section{Mercado de trabalho: a importância da possibilidade de inserção e/ou permanência}

A motivação dos participantes trabalhadores direcionada à formação no ensino superior parece estar relacionada à inserção mais rápida no mercado de trabalho e de melhoria de qualidade de vida, incluída a expectativa, para a maioria, de continuar na área de trabalho já exercida, no caso, a enfermagem.

Essa ideia faz sentido quando associada também à caracterização dos participantes deste estudo, oriundos, na maioria, de mães e pais com ensino fundamental incompleto. Assim, os participantes fizeram uma trajetória além dos pais, em termos de estudo, com a intenção de facilitara inserção no mercado de trabalho e melhorar as condições concretas de vida.

E eu não sabia o que fazer. Então, falei: "Qual curso que eu ia ter emprego logo?" E tinha uma vizinha que fazia um curso de Enfermagem. Em seguida ela já arrumou serviço. (...) Nunca me imaginei na Enfermagem (...). E06

(...) o fato de gostar e também ter uma ascensão profissional, né. E05

No presente estudo, todavia, apenas um participante relatou que as expectativas voltadas à ascensão econômica foram atendidas, informando, principalmente, maior acesso a bens e serviços para si e os familiares.

(...) eu acho que uma questão de conforto né, casa, carro, viagens, essas coisas mais palpáveis aí que você, tem uma condição financeira um pouco melhor, poder dar um estudo melhor para os meus filhos do que eu tive (...) com maiores chances aí dele estar prestando um vestibular, e estar sendo aprovado, enfim, nesse sentido assim (E01) 
A busca pela formação no ensino superior de profissionais técnicos de nível médio em enfermagem foi descrita também em pesquisa com o objetivo de identificar o perfil de formação da equipe de enfermagem em território nacional, constituída por enfermeiros, técnicos e auxiliares de enfermagem (MACHADO; WEMELINGER; VIEIRA et al., 2016).

Porém, a busca por melhoria da qualidade de vida, não claramente exposta pelos participantes deste estudo, mas apontada por estudos anteriormente citados e relacionada à possibilidade de atuação em apenas um emprego e melhorias em condições salariais, encontra algumas discrepâncias na literatura atual no que se refere às condições concretas postas pelo mercado de trabalho.

No estágio atual do capitalismo, o papel econômico da educação é revalorizado no sentido não mais da associação com o desenvolvimento econômico e da integração social dos indivíduos, mas no sentido de aumentar as chances de inserção no mercado de trabalho, aumentando a empregabilidade por esforços individuais. Entretanto, embora no decorrer da formação sejam fornecidos estímulos para o esforço e responsabilização individual pelo "sucesso" no mercado de trabalho, as classes econômicas e culturalmente mais favorecidas permanecem possuindo maior potencial de inserção no mercado de trabalho, pois não se trata apenas do acesso a níveis mais intelectualizados de ensino, mas de condições concretas de vida e acesso a conhecimentos historicamente organizados (LEMOS; DUBEUX; PINTO, 2009).

A partir da realização de uma síntese de documentos internacionais, baseados em princípios presentes na globalização neoliberal, que vêm norteando as políticas educacionais, Charlot (2005) comenta que a educação, submetida aos padrões do mercado capitalista, vem sendo enfocada em lógica econômica e como preparação para o mercado de trabalho, sendo os trabalhadores considerados "empregáveis", "flexíveis", "competitivos", o que vem de encontro ao princípio da educação como direito social garantido e financiado pelo Estado.

As mudanças nas relações de trabalho também têm repercussões na enfermagem. A enfermagem vem demonstrando problema de empregabilidade plena. Mais de 182 mil profissionais que compõem a equipe de enfermagem 
declararam ter experimentado condições de desemprego nos últimos 12 meses (MACHADO; WEMELINGER; VIEIRA et al., 2016).

Percebe-se, portanto, que a busca pela ascensão social vinculada ao aumento de renda mensal, quando comparada com a recebida como técnicos e/ou auxiliares de enfermagem, parece ser plausível, embora a composição do mercado de trabalho para a enfermagem seja descrita pelos autores (MACHADO; WEMELINGER; VIEIRA et al., 2016) como desfavorável no quesito econômico.

\section{A trajetória do trabalhador estudante durante a formação na IES}

No que se refere à relação com professores, as vivências relatadas enfocaram as exigências exercidas por alguns professores quanto ao cumprimento de horários nos cenários de estágio, principalmente, durante o estágio curricular obrigatório nos serviços de saúde. Uma vez anunciadas essas exigências, os participantes relataram que a forma de resolução encontrada foi um esforço para além do esperado para mostrar comprometimento e envolvimento nas atividades.

(...) Quando, no final do curso, que os estágios eram horários de trabalho, que eu tinha que estar lá no horário que estava saindo do meu, aí complicava. Aí a gente tentava conversar com o professor de chegar uns minutinhos depois, ficar um tempo depois. E ir adaptando assim. Teve uns que a gente conseguia. Outros não. Então, a gente acabava meio que tendo que se virar nos trinta (...). E02

Percebe-se, a partir das falas dos participantes, que a dificuldade de cumprimento de horários, principalmente durante o desenvolvimento do estágio curricular supervisionado, decorreu do desafio da própria conciliação entre trabalho e estudo, uma vez que a maioria dos participantes exercia atividade remunerada como auxiliares/técnicos de enfermagem e os horários de final de plantão em instituições de saúde culminam no início de outro plantão de trabalho a ser cumprido no estágio.

Assim, quando houve esforços por parte de alguns alunos em colocar suas questões e dificuldades de horário, foram relatadas reações de alguns professores de 
certo distanciamento do contexto do qual o aluno é oriundo, e exigido, apenas, que priorizassem a formação.

(...) eu encontrei, sim, alguns empecilhos (...) às vezes que eu não conseguia ser liberada do trabalho, mais cedo, porque eu trabalhava numa sala de urgência, então, nem sempre o paciente chegando, não conseguia sair, mas, justamente, pelo atendimento ao paciente. E tinha, realmente, me pedir para fazer escolhas. De falar: você precisa escolher (...)"eu tinha que ter uma prioridade, ou tinha que trabalhar ou tinha que estudar. E03

Embora não possa ser considerada como a expressão e compreensão do corpo docente completo do curso, algumas vivências de tentativa de diálogo com professores na questão do cumprimento de horário de chegada nos estágios foram relatadas, pelos entrevistados, como permeadas explicitamente por preconceito dos professores no que se refere à inserção dos trabalhadores

Já outras experiências, não quero pôr o nome de quem foi, assim, eu já ouvi aqui: "O que você está fazendo aqui? Aqui não é lugar para quem trabalha". Como se eu tivesse outra opção. Então, foi muito ruim isso. Mas eu falei assim: "Se eu estou aqui, eu vou permanecer (...) Particular. Bem particular. Uma pessoa dessa não ia falar isso em público. De jeito nenhum. (...) Professor. Isso foi de professor (...). E06

Enfocando as problemáticas de conciliar trabalho e o início do turno noturno em IFES na cidade do Rio de Janeiro, é afirmado, no estudo de Vargas e Paula (2013), que as instituições foram historicamente voltadas para a elite, não sendo reconhecido, a partir das condições de trabalhadores alunos que chegam cansados e desgastados em sala de aula, o perfil de aluno desenhado e desejado, para conformar a democratização da educação superior no Brasil. Há, assim, dificuldades relativas tanto à proteção legal do estudante que trabalha ou do trabalhador que estuda, bem como à adequação pedagógica.

Vivências semelhantes relacionadas a dificuldades também foram relatadas na relação com alguns colegas não trabalhadores. Alguns participantes relataram que, devido ao fato da maioria dos colegas não ser trabalhador, em algumas situações, não havia compreensão e acordos que olhassem para a condição de vida específica da minoria. 
(...) Às vezes, eu tinha sempre o hábito de sentar lá na frente, porque o meu momento de aprender era aquele. E se eu pegasse e falasse: "Professor, não entendi". Não foi uma, não foi duas vezes, que eu vi colegas fazerem assim: "De novo?"(...) E04

Cabe considerar, entretanto, que em meio a dificuldades apresentadas na relação entre professores / colegas e trabalhadores estudantes, houve relatos que vão em outra direção, mencionando que alguns professores e colegas exerceram importante papel de apoio ao trabalhador estudante.

(...) Mas também tive anjos da guarda, né, professores que chegaram e falaram, assim, a hora que você chegar inicia o seu plantão. Não é para morrer no meio do caminho. Entendeu? Então, assim, foi bem... teve, sim, teve empecilho, mas tiveram pessoas muito boas. E03

(...) Porque no começo também, até na faculdade, eu tinha que trazer o meu filho. $E$, às vezes, as meninas da turma seguravam ele para eu poder ficar um pouco na aula, senão, eu não ia aproveitar nada da aula (...). E05

Para romper dificuldades, na conciliação trabalho e estudo, principalmente oriundas de certa compreensão de alguns docentes sobre condições concretas de vida do trabalhador estudante, os participantes do estudo apresentaram um movimento que se aproxima do reconhecimento de um sentimento de serem vencedores na luta pela sua manutenção na universidade e não como um direito de acesso e de condições para estudo. Essa luta também é permeada por alguns apoios importantes, havendo, porém, necessidade de maior compreensão entre o tênue limite entre o apoio, como compromisso institucional, no contexto do direito à educação, ou como situações que apenas são percebidas como expressões de bondade de algumas pessoas individualmente.

Nessa luta, subentende-se que fica mais a cargo do sujeito estudante a responsabilização de concretizar ou não o planejado no contexto do processo ensino-aprendizagem. E vai sendo explicitado que cabe aos professores, individualmente, tomar decisões sobre a organização das atividades para esses alunos, denotando limites na construção de política institucional que acolhe e integra, sem preconceitos, o trabalhador. 
(...) O que muitas vezes a gente comentava, é que, assim, nós trabalhávamos, nós tínhamos um horário corrido, nós procurávamos o máximo de comprometimento possível, principalmente, com relação a trabalhos, a portfólio, a campo de estágio, a desenvolver as atividades pra apresentação em sala. E06

Os relatos dos trabalhadores estudantes vão em direção a uma busca individual de romper empecilhos e concluir aquilo que parece ser um projeto pessoal de vida, sem que haja, em alguns momentos, a consideração de suas condições por parte dos outros sujeitos envolvidos no processo de formação.

Compreende-se que seja fundamental o enfoque da formação, junto aos alunos, trazendo-os para o comprometimento e responsabilidade com as disciplinas do curso, as atividades propostas, porém, quando entrevistados se referem, a partir de falas de alguns professores do curso, a situações polarizadas como: (...) eu tinha que trabalhar ou tinha que estudar. (E03) ou ainda (...) você tem que ver sua prioridade (E07), pode ser apreendida uma situação que, de fato, é desconsiderado que, para alguns alunos, o trabalho não se trata de simples escolha, mas de necessidade, tendo em vista as condições concretas de vida e, assim, que se trata de tentativa árdua de conciliação entre trabalho e estudo, cabendo ressaltar, inclusive, a caracterização de algumas participantes como mulheres, casadas, com filhos.

Nesse sentido, torna-se preciso retomar como a formação e a atuação docente se configuram no cenário educacional de ensino superior. A expansão do ensino superior, principalmente a partir do início do século XXI, é caracterizada, por um avanço quantitativo do acesso a esse nível de ensino. A partir disso, os professores universitários se viram frente a um novo contexto educacional, formado, ainda que em sua minoria, por alunos provenientes de classes sociais até então não inclusas no ensino superior (SÔNEGO, 2015).

As demandas para a atuação docente provenientes de um alunado diferente do que vinha sendo incluído no ensino superior confrontam-se com uma formação docente que apresenta limites uma vez que se dá por meio de programas de pósgraduação amplamente focados na formação para a pesquisa científica, com formação deficitária no que concerne aos saberes docentes (SÔNEGO, 2015).

Professores com limites na formação para a docência podem restringir a sua atuação a uma dimensão técnica na qual vários aspectos, sem dúvida, importantes, 
precisam ser cumpridos, porém, sem maiores análises acerca do contexto políticoeconômico e social no qual atuam, envolvendo as políticas públicas do ensino envolvidos no processo ensino-aprendizagem (LIMA; BRAGA, 2016).

$\mathrm{Na}$ universidade, é importante que a prática se organize em torno de negação da dominação e da reprodução da estrutura social vigente (LIMA; BRAGA, 2016). Torna-se preciso, então, que o professor universitário compreenda que a sua atuação é parte de um processo educacional maior, e que a instituição de ensino retrata e reproduz os contextos sociais e históricos, mas também projeta a sociedade que se deseja (SÔNEGO, 2015).

Quando os participantes relatam falas de professores no sentido de que o trabalhador não deveria estar nesse contexto educacional específico, reflete-se uma lógica de formação do trabalhador não inclusa no ensino superior.

Uma vez fundamentada não no sujeito, mas nas bases econômicas vigentes, a formação para o trabalhador fica restrita à formação para atividades manuais e de fácil absorção no mercado de trabalho, enquanto para a elite, o ensino superior se caracteriza como meio para o acesso a saberes intelectualizados (CIAVATTA; RAMOS, 2011).

Apesar de serem reconhecidos alguns limites e questionados alguns preconceitos, os entrevistados se expressam como indivíduos lutadores e vencedores, não sendo feitas relações mais claras entre a sua inserção e permanência no ensino superior com o contexto político, econômico e social mais amplo. Ou seja, de certo modo, são naturalizadas as situações enfrentadas, envolvendo as suas condições de vida. Em nenhum dos relatos houve, por exemplo, algum questionamento sobre o contexto oriundo dos participantes, do porquê, para eles, era necessário conciliar trabalho, estudo e contexto familiar, lidando com adversidades, enquanto para outros, as condições eram favoráveis ao estudo.

A fundamentação das políticas públicas para o sistema de ensino brasileiro decorre, no atual momento histórico, da lógica neoliberal, que promove processos formativos, desde a educação básica, que fortalecem no sujeito o discurso que privilegia a competitividade, a individualidade e a eficiência. Essa concepção está intrínseca na formação desde a educação básica, constituída como instrumento para 
formar trabalhadores mais adaptáveis e flexíveis às demandas impostas pelo mercado de trabalho (GIRON, 2008).

Sendo assim, a educação é compreendida como uma promessa de mudança situacional do indivíduo isoladamente, em meio a um contexto econômico marcado pelo desemprego estrutural, na qual cabe ao indivíduo a responsabilização individual pela inserção no mercado de trabalho. Assim, a educação deixa de ser um processo de formação do indivíduo social e torna-se instrumento para atender a demandas mercadológicas (NOMA; KOEPSEL; CHILANTE, 2010).

Nesse contexto, pode ser deflagrada, a lógica da sociedade da informação. Charlot (2005) comenta que a informação e o saber são distintos. A informação é somente o enunciado de um fato. Fato esse que pode, inclusive, ser explorado para o ganho financeiro; o saber tem início a partir do momento em que o conhecimento desse fato passa a produzir sentido "sobre o mundo, sobre a vida, sobre os outros, sobre mim mesmo”. Assim, afirma o autor que temos cada vez mais informações, todavia, essas "produzem cada vez menos sentido, saber e cultura" (CHARLOT, 2005, p. 139).

\section{Considerações finais}

Nas últimas décadas, no Brasil, tem havido um processo de expansão do ensino superior a partir de políticas internacionais na perspectiva neoliberal, como também houve propostas políticas públicas de ensino superior que favoreceram a ampliação e o fortalecimento de IES públicas e o desenvolvimento de políticas de inclusão e permanência estudantil.

$\mathrm{Na}$ área da enfermagem houve, também, expansão de vagas, principalmente em cursos noturnos em IES privadas. Considerando política de ampliação de vagas das IES estaduais no estado de São Paulo, com foco no ensino superior noturno, teve início o curso de Bacharelado e Licenciatura em Enfermagem de uma Universidade pública do estado de São Paulo, com oferta de vagas no período vespertino/noturno, em 2006. Nesse contexto, apresentou-se a possibilidade de inserção do trabalhador estudante nesse curso.

Os trabalhadores estudantes entrevistados vislumbraram a possibilidade de conciliar trabalho e estudo, dado o horário de oferecimento do mesmo. Somado a 
isso, a trajetória prévia construída na educação básica pública apresentou-se como fator limitador para a continuação dos estudos, já que, em sua maioria, os participantes apenas pensaram sobre a possibilidade de formação de nível superior por meio de influências externas, como o contato com pessoas conhecidas, e não como projeto de vida processualmente construído pelo próprio sujeito.

Nesse sentido, as motivações para o ingresso no ensino superior foram demarcadas, de certo modo, pela dualidade estrutural do sistema escolar brasileiro, sendo os percursos educacionais dos sujeitos relacionados à divisão de classes sociais, cabendo o ensino superior à classe social privilegiada economicamente. Ou seja, na fala dos entrevistados, é relatado certo distanciamento vivido por eles em relação à possibilidade de inserção no ensino superior.

A procura pelo curso apresentou-se ainda como uma possibilidade de inserção rápida ou permanência no mercado de trabalho, associada, em se tratando de alguns, ao que parece ser uma ascensão que perpassa a hierarquização social e econômica da equipe de enfermagem. Cabe também considerar que a escolha profissional pelo curso que forma enfermeiro licenciado, com perspectiva de entrada rápida no mercado de trabalho, pode ter relações com o fato dos participantes serem provenientes de famílias cujos pais e mães cursaram, em sua maioria, apenas até o ensino fundamental.

Tais relatos associados à inserção no mercado de trabalho podem, de certo modo, denunciar a busca pelo ensino superior restrita ao saber fazer. Entretanto, dados de pesquisa apontam a composição de um mercado de trabalho para a área não tão favorável.

Algumas vivências dos trabalhadores estudantes envolveram o não reconhecimento do direito da sua inserção no curso, sendo marcadas por preconceitos de professores e colegas. Tais vivências podem mostrar limites no que se relaciona ao reconhecimento do papel social e político da educação, trazendo implicações na tomada de decisões sobre os processos educativos na IES.

Destaca-se que, em meio a essas vivências, os participantes valorizaram a trajetória individualizada, com certa naturalização da responsabilização individual pelo "sucesso" ou "fracasso" da formação. Esse cenário está em consonância com a lógica neoliberal que aponta a educação como uma promessa de melhoria de vida, 
porém, cabendo apenas ao indivíduo a sua concretização, negando, assim, a teia de relações coletivas que se configuram, produzidas em dada estrutura social, trazendo implicações às trajetórias individuais.

O ingresso da classe trabalhadora, proveniente da educação básica pública, nas IES, precisa ser considerado em um contexto marcado por algumas dimensões como: o modo como essas instituições vêm sendo organizadas, nas últimas décadas, com avanço significativo da lógica neoliberal, imprimindo mudanças nas formas de trabalho docente e no foco da formação; os limites concernentes à formação dos professores universitários para a docência; o esvaziamento da perspectiva crítica de educação a favor da lógica instrumental. Trata-se de dimensões fundamentais que precisam ser refletidas e analisadas nas suas relações mais amplas com a estrutura social do país, com a estrutura dual do sistema educacional, com as políticas de educação superior.

Nesse contexto, considerando a instituição envolvida neste estudo, acreditaque os resultados obtidos podem subsidiar reflexões sobre a forma que a inserção de trabalhadores, no contexto de expansão de vagas no ensino superior, tem sido compreendida pelos egressos e quais seus significados, tendo em vista o projeto de formação que se intenciona construir.Essas reflexões, provavelmente, tornar-se-ão realizáveis à medida em que forem produzidos espaços coletivos de formação docente e de tomada de decisões institucionais.

Nessa direção, investir em estudos futuros acerca das concepções presentes no próprio curso, fortalecendo a visão de educação como direito social será importante, considerando, inclusive, que o aluno é também formado para a docência na educação profissional.

\section{Referências}

AGUIAR, M. A. S. Avaliação do Plano Nacional de Educação 2001-2009: questões para reflexão. Educ. Soc., Campinas, v. 31, n. 112, p. 707-27, 2010.

BARDIN, L. Análise de conteúdo. São Paulo: Edições 70, 2016.

BARREIRO, I. M. F.; TERRIBILI FILHO, A. Educação superior no período noturno no Brasil: políticas, intenções e omissões. Ensaio: Aval. Pol. Públ. Educ., v. 15, n. 54, p. 81-102, 2007. 
BERTELLI, E.; TUMELERO, S. M.; LAZARIN, S. M. "A vida como ela é": gênero, trabalho e família. In: FAZENDO GÊNERO: DIÁSPORAS, DIVERSIDADES, DESLOCAMENTOS, 9., 2010, Florianópolis. Anais... Florianópolis: UFSC, 2010.

BUBLITZ, S. et al. Perfil sociodemográfico e acadêmico de discentes de enfermagem de quatro instituições brasileiras. Revista Gaúcha de Enfermagem/EENFUFRGS, v. 36, n. 1, p. 77-83, 2015.

BRASIL. Ministério da Educação. Instituições de Educação Superior e Cursos Cadastrados: Busca interativa. 2019. Disponível em: http://emec.mec.gov.br/. Acesso em: 04 dez. 2019.

BRASIL. Ministério da Educação. Relatório de Área: Enfermagem. Brasília; INEP, 2013.

CAMPELLO, A. M. Fundação Oswaldo Cruz. Escola Politécnica de Saúde Joaquim Venâncio. Dualidade 2019. Disponível em: http://www.sites.epsjv.fiocruz.br/dicionario/verbetes/duaedu.html. Acesso em: 04 dez. 2019.

CHARLOT, B. Relação com o saber, formação dos professores e globalização - questões para a educação*o de hoje. Porto Alegre: Artmed, 2005.

CIAVATTA, M.; RAMOS, M. Ensino médio e educação profissional no Brasil: dualidade e fragmentação. Rev. Retratos da Escola, v. 5, n. 8, p. 27-41, 2011.

CORRÊA, A. K.; SOUZA, M. C. B. M.; CLAPIS, M. J. Formação de professores para educação profissional em enfermagem: reflexões a partir de um curso de bacharelado e licenciatura. In: CORREAA, A. K.; SOUZA, M. C. B. M. Formação de professores em debate: educação superior, educação profissional e licenciatura em enfermagem. Paraná: CRV, 2016.

CORRÊEA, A. K. et al. O perfil do aluno ingressante em um curso de Bacharelado e Licenciatura em Enfermagem de uma instituição de ensino superior pública. Educação em Revista, Belo Horizonte, n. 34, e185913, p. 1-34, 2018.

CUNHA, L. A. O ensino superior no octênio FHC. Educ. Soc., Campinas, v. 24, n. 82, p. 35-61, 2003.

CUNHA, L. A. O legado da ditadura para a educação brasileira. Educ. Soc., Campinas, v. 35, n. 127, p. 357-377, 2014.

DIAS SOBRINHO, J. Universidade fraturada: reflexões sobre conhecimento e responsabilidade social. Avaliação, Campinas; Sorocaba, v. 20, n. 3, p. 581-601, 2015.

DINIZ, R. V.; GOERGEN, P. L. Educação superior no Brasil: panorama da contemporaneidade. Avaliação, Campinas; Sorocaba, v. 24, n. 03, p. 573-593, 2019.

DURHAM, E. R. Desigualdade educacional e cotas para negros nas universidades. Novos Estudos. CEBRAP, S. Paulo, v. 66, p. 3-22, 2003.

FILHO, A. T.; RAPHAEL, H. S. Fatores de atrasos e faltas do estudante do ensino superior noturno: a perda de aulas, de provas e o impacto no seu aproveitamento e em avaliações. Avaliação, v. 10, n. 2, p. 117-35, 2005. 
GIRON, G. R. Políticas públicas, educação e neoliberalismo: o que isso tem a ver com cidadania?. Revista de Educação PUC-Camp., v. 24, p. 17-26, 2012.

GIROTTO, E. D. A classe trabalhadora vai à universidade: análise das implicações políticopedagógicas a partir dos dados do departamento de geografia - USP. Revista da Associação Nacional de Pós-graduação e Pesquisa em Geografia (Anpege), v. 13, n. 20, p. 209-235, 2017.

GIROUX, H. Ensino superior, para quê?. Educar, Curitiba, n. 37, p. 25-38, 2010.

LAKATOS, E. M.; MARCONI, M. Metodologia Científica. 7. ed. São Paulo: Atlas, 2017.

LEMOS, A. H. C; DUBEUX, V. J. C; PINTO, M. C. S. Educação, empregabilidade e mobilidade social: convergências e divergências. Cad. EBAPE.BR., v. 7, n. 2, p. 368-84, 2009.

LIMA, M. S. L.; BRAGA, M. M. S. C. Relação ensino-aprendizagem na docência: traços da Pedagogia de Paulo Freire no Ensino Superior. Educar em Revista, v. 61, p. 71-88, 2016.

MACHADO, M. H. et al. Aspectos gerais da formação da enfermagem: o perfil da formação dos enfermeiros, técnicos e auxiliares. Enfermagem em foco, v. 6, n. 2/4, p. 15-34, 2016.

MANCEBO, D. Crise político-econômica no Brasil: breve análise da educação superior. Educ. Soc., Campinas, v. 38, n. 141, p.975-92, 2017.

MANCEBO, D. Trabalho docente na educação superior brasileira: mercantilização das relações e heteronomia acadêmica. Rev. Port. Educ., v.23, n.2, p.73-91, 2010.

MINAYO, M. C. S. Análise qualitativa: teoria, passos e fidedignidade. Ciênc. saúde coletiva, v. 17, n. 3, p. 621-26, 2012.

NARDELLI, G. G. et al. Perfil dos alunos ingressantes dos cursos da área da saúde de uma Universidade Federal. Revista de Enfermagem e Atenção à Saúde, v. 2, n. 1, p. 3-12, 2013.

NOMA, A. K.; KOEPSEL, E. C. N.; CHILANTE, E. F. N. Trabalho e educação em documentos de políticas educacionais. Revista HISTEDBR, especial, p. 65-82, 2010.

OLIVEIRA, R. Precarização do trabalho: a funcionalidade da educação profissional. Rev. Diálogo Educ., v. 15, n. 44, p. 245-66, 2015.

PALAZZO, J.; GOMES, C. A. Origens sociais dos futuros educadores: a democratização desigual da educação superior. Revista da Avaliação da Educaşão Superior (Avaliação), v. 17, n. 3 , p. $877-898,2012$.

PINTO, M. J. R. O acesso à educação superior no Brasil. Educação e Sociedade, v. 25, n. 88 , p. $727-56,2004$.

PIOTTO, D. C.; ALVES, R. O. O ingresso de estudantes das camadas populares em uma universidade pública: desviando do ocaso quase por acaso. Rev Educ PUC-Camp., v. 21, n. 2, p. 139-147, 2016.

POUPART, J. et al. A pesquisa qualitativa: enfoques epistemológicos e metodológicos. 4. ed. Rio de Janeiro: Vozes, 2014. 
PREBILL, G. M.; CORREAA, A. K. O trabalhador-estudante de enfermagem: um estudo bibliográfico. Ciência, Cuidado e Saúde, v. 17, n. 4, p. 1-6, 2018.

RISTOFF, D. O novo perfil do campus brasileiro: uma análise do perfil socioeconômico do estudante de graduação. Avaliação, Campinas, v. 19, n. 3, p. 723-747, 2014.

SGUISSARDI, V. Educação superior no Brasil: democratização ou massificação mercantil? Revista Educ. Soc., Campinas, v. 36, n. 133, p. 867-889, 2015.

SIGNORI, Z. M. M.; CAMPANELLI, R. T. B. A escola e a formação do trabalhador: a questão da dualidade estrutural. Pedagogia em Foco, v. 10, n. 40, p. 156-67, 2015.

SIMÕES, C. A. Educação técnica e escolarização de jovens trabalhadores. In: MOLL, J. (Org.). Educação profissional e tecnológica no Brasil contemporâneo. Porto Alegre: Artmed, 2010.

SÔNEGO, A. Os desafios da universidade no século XXI e algumas reflexões sobre a posição docente frente a este processo. Rev. Bras. de Ensino Superior, v. 1, n. 1, p. 30-35, 2015.

SOUZA, N. V. D. O. et al. Perfil socioeconômico e cultural do estudante ingressante no curso de graduação em enfermagem. Rev. Enferm. UERJ, v. 21, n. esp.2, p. 718-22, 2013.

SPÍNDOLA, T. et al. Enfermagem como opção: perfil de graduando de duas instituições de ensino. Revista Brasileira de Enfermagem - REBEN, v. 61, n. 2, p. 164-9, 2008.

TERRIBILI FILHO, A.; RAPHAEL, H. S. Fatores de atrasos e faltas do estudante do ensino superior noturno: a perda de aulas, de provas e o impacto no seu aproveitamento e em avaliações. Avaliação, v. 10, n. 2, p. 117-35, 2005.

VARGAS, H. M; PAULA, M. F. C. A inclusão do estudante-trabalhador e do trabalhadorestudante na educação superior: desafio público a ser enfrentado. Avaliação, Campinas, v. 18, n. 2, p.459-84, 2013.

ZAGO, N. Do acesso à permanência no ensino superior: percursos de estudantes universitários de camadas populares. Rev. Bras. Educ., Rio de Janeiro, v. 11, n. 32, p. 226-37, 2006.

ZAGO, N.; PAIXÃO, L. P.; PEREIRA, T. I. Acesso e permanência no ensino superior: problematização da evasão em uma nova universidade federal. Educação em foco, v. 19, n. 27, p. 145-69, 2016.

RECEBIDO: 07/04/2020

APROVADO: 29/07/2020
RECEIVED: 04/07/2020

APPROVED: 07/29/2020
RECIBIDO: 07/04/2020

APROBADO: $27 / 07 / 2020$ 